\title{
Seismicity gap and seismic quiescence before 1999 Jiji (Chi-Chi) $M_{W} 7.6$ earthquake*
}

\author{
Junguo Wang ${ }^{*}$ Wenbing Liu and Jieqing Zhang \\ Earthquake Administration of Tianjin Municipality, Tianjin 300201, China
}

\begin{abstract}
The September 21, 1999, Jiji (Chi-Chi) $M_{\mathrm{W}} 7.6$ earthquake is the strongest event occurred since 1900 in Taiwan of China. It is located in the middle segment of the western seismic zone of Taiwan. Based on several versions of China earthquake catalogue this study found that a seismic gap of $M \geq 5$ earthquakes appeared, in and around the epicenter region, 24 years before and lasted up to the mainshock occurrence. This study also noticed that there existed a lager seismically quiet region of $M \geq 4$ earthquakes, which lasted for about 2.5 years before the mainshock occurrence. The spatial variation pattern of regional seismicity before the mainshock seems to match with its coseismic source rupture process. The mentioned seismicity gap and seismic quiescence might be an indication of the preparation process of the Jiji strong earthquake.
\end{abstract}

Key words: Taiwan; Jiji (Chi-Chi) earthquake; seismicity gap; seismic quiescence

CLC number: P315.5 Document code: A

\section{Introduction}

On September 21, 1999, a $M_{\mathrm{W}} 7.6$ strong earthquake occurred in Jiji (Chi-Chi), Nantou county in the central part of Taiwan, China. The epicenter location determined by China Earthquake Networks is $23.97^{\circ} \mathrm{N}$, $120.75^{\circ} \mathrm{E}$ and the depth of seismic focus is $5 \mathrm{~km}$. The final epicenter location issued by the Seismological Center of Taiwan Weather Bureau is $23.86^{\circ} \mathrm{N}, 120.81^{\circ} \mathrm{E}$ and the depth of seismic focus is $11 \mathrm{~km}$. The focal mechanism solutions for the Jiji $M_{\mathrm{W}} 7.6$ earthquake calculated by $\mathrm{Xu}$ et al (1999), Harvard University and United States Geological Survey are shown in Table 1.

The seismicity characteristics in Taiwan are studied in this paper. Before the Jiji $M_{\mathrm{W}} 7.6$ earthquake, distinct seismicity gap and seismic quiescence were discovered. They were similar to the anomalies appeared before the great earthquakes occurred in Chinese mainland.

Table 1 Parameters of focal mechanism solution of the 1999 Jiji $M_{\mathrm{W}} 7.6$ earthquake

\begin{tabular}{|c|c|c|c|c|c|c|c|c|c|c|c|}
\hline \multirow[b]{2}{*}{ No. } & \multicolumn{2}{|c|}{$P$-axis } & \multicolumn{2}{|c|}{$T$-axis } & \multicolumn{3}{|c|}{ Nodal plane I } & \multicolumn{3}{|c|}{ Nodal plane II } & \multirow[b]{2}{*}{ Resource } \\
\hline & $\begin{array}{c}\text { Azimuth } \\
/^{\circ}\end{array}$ & $\begin{array}{c}\text { Dip } \\
\text { angle } /{ }^{\circ}\end{array}$ & $\begin{array}{c}\text { Azimuth } \\
/{ }^{\circ}\end{array}$ & $\begin{array}{c}\text { Dip } \\
\text { angle } /{ }^{\circ}\end{array}$ & $\begin{array}{c}\text { Strike } \\
10\end{array}$ & $\begin{array}{c}\text { Dip } \\
\text { angle }^{\circ}\end{array}$ & $\begin{array}{c}\text { Slip } \\
\text { angle }^{\circ}\end{array}$ & $\begin{array}{c}\text { Strike } \\
/{ }^{\circ}\end{array}$ & $\begin{array}{c}\text { Dip } \\
\text { angle } /^{\circ}\end{array}$ & $\begin{array}{c}\text { Slip } \\
\text { angle }^{\circ}\end{array}$ & \\
\hline 1 & 290 & 17 & 115 & 73 & 17 & 28 & 87 & 201 & 62 & 92 & Xu et al (1999) \\
\hline 2 & 302 & 19 & 133 & 71 & 26 & 27 & 82 & 215 & 64 & 94 & Harvard University \\
\hline 3 & 297 & 17 & 138 & 69 & 357 & 29 & 67 & 202 & 63 & 102 & United States Geological Survey \\
\hline
\end{tabular}

\section{Regional tectonic environment and historical intensive seismicity}

As a part of circum-Pacific seismic zone, Taiwan is located at the collision intersection of the Eurasia, Pa-

\footnotetext{
* Received 1 April 2010; accepted in revised form 12 June 2010; published 10 August 2010.

* Corresponding author. e-mail: junguo_wang@sina.com

(C) The Seismological Society of China and Springer-Verlag Berlin Heidelberg 2010
}

cific and Philippine Sea plates, where seismic intensity and earthquake frequency are the highest in China. Seno (1977) indicated the Philippine Sea plate drives in the WNW direction with an average rate of $7 \mathrm{~cm} / \mathrm{a}$. In the southwestern part of Taiwan, the Eurasia plate has an eastwards underthrust along the Manila trench to the underneath of the Philippine Sea plate; while in the northeastern part of Taiwan, the Philippine Sea plate has a northwestwards underthrust along the Ryukyu trench to the underneath of the Eurasia plate (Angelier, 1986). Therefore, the convergence of plates in this area is com- 
plex. And the longitudinal valley in the eastern Taiwan, which is located between the central range and the coastal range, is the collision suture line of the two plates on the Earth's surface.

Many historical data (Gu, 1983a, b; Department of Seismic Hazard Prevention, China Seismological Bureau, 1999) indicated the historical earthquake in Taiwan occurred as early as the year 1624. During the period from 1900 to the time before the 1999 Jiji $M_{\mathrm{W}} 7.6$ earthquake, totally $41 \quad M \geq 7$ earthquakes (two of them were $M 8$ earthquakes) occurred, and most of them were in the sea area to the east of Taiwan (Figure 1). The seismicity in Taiwan is characterized by a NNE-trending distribution, which is consistent with the trends of margins of geological structures like the large sea fault on the east of Taiwan, the longitudinal valley in the eastern Taiwan and the fore down-warping subsidence in the western Taiwan, respectively, as well as the strike of interior faults in Taiwan island. There are three major seismic zones: western seismic zone, eastern seismic zone and northeastern seismic zone (Ye and Huang, 1992).

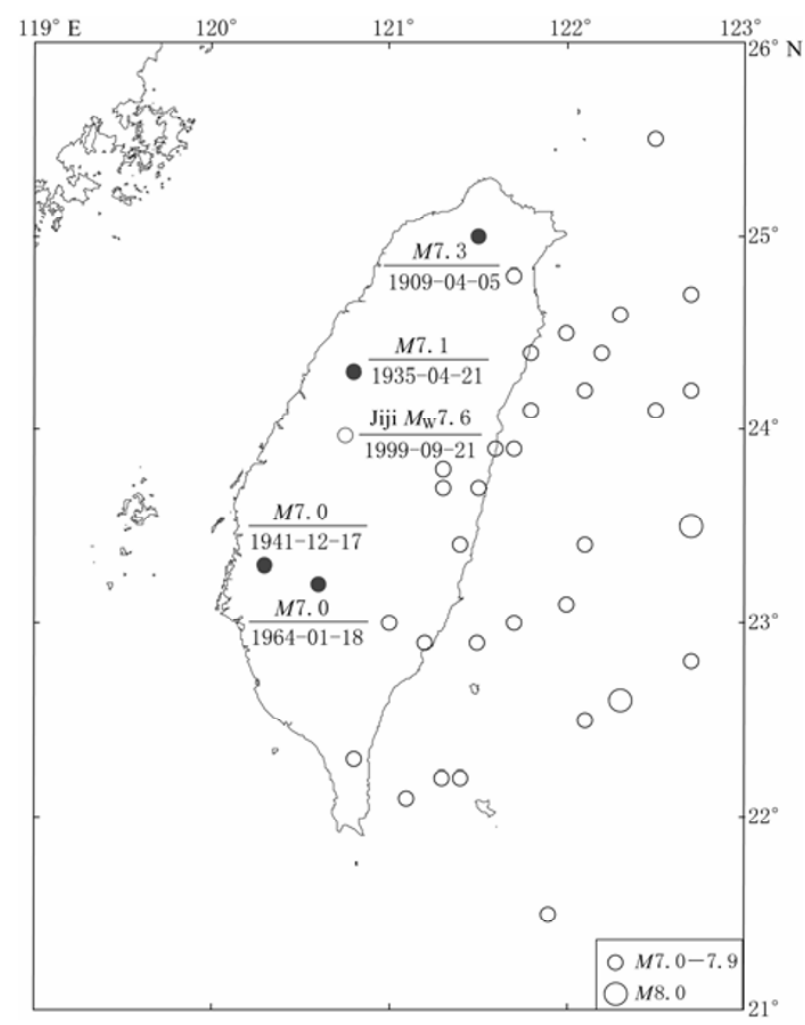

Figure 1 Spatial distribution of $M \geq 7$ earthquakes in Taiwan island from 1900 to 1999 (from China Earthquake Networks). The four earthquakes denoted by solid circles manifest a transfer line of $M 7$ earthquakes with time from the north to the south along the western seismic zone.
The epicenter of Jiji $M_{\mathrm{W}} 7.6$ earthquake was just located in the middle segment of western seismic zone (Figure 2), and it is the most intensive earthquake in the historical records in Taiwan (Table 2). Stretching in the NNE trend in the coastal plain area along the west margin of Taiwan, the western seismic zone is approximately parallel to the axial line of Taiwan island. With a width of $80 \mathrm{~km}$, it starts from Taipei and passes through Hsinchu, Taichung, Chia-i to Tainan, covering the large area on the south of Taoyuan county and Pingtung county in the western part of Taiwan. Four $M \geq 7$ earthquakes occurred here since 1900 , amounting to $40 \%$ of the $M \geq 7$ earthquakes in Taiwan. The $M 7.3$ earthquake near Taipei in 1909 , the $M 7.1$ earthquake near Taichung in 1935, the M7.0 earthquake near Tainan in 1941 and the M7.0 earthquake to the southeast of Tainan in 1964, manifest a transfer line of $M 7$ earthquakes with time from the north to the south along the western seismic zone, while the Jiji earthquake turned back northwards from this line to the middle segment of the western seismic zone. The time interval is 64 years and the spatial span is about

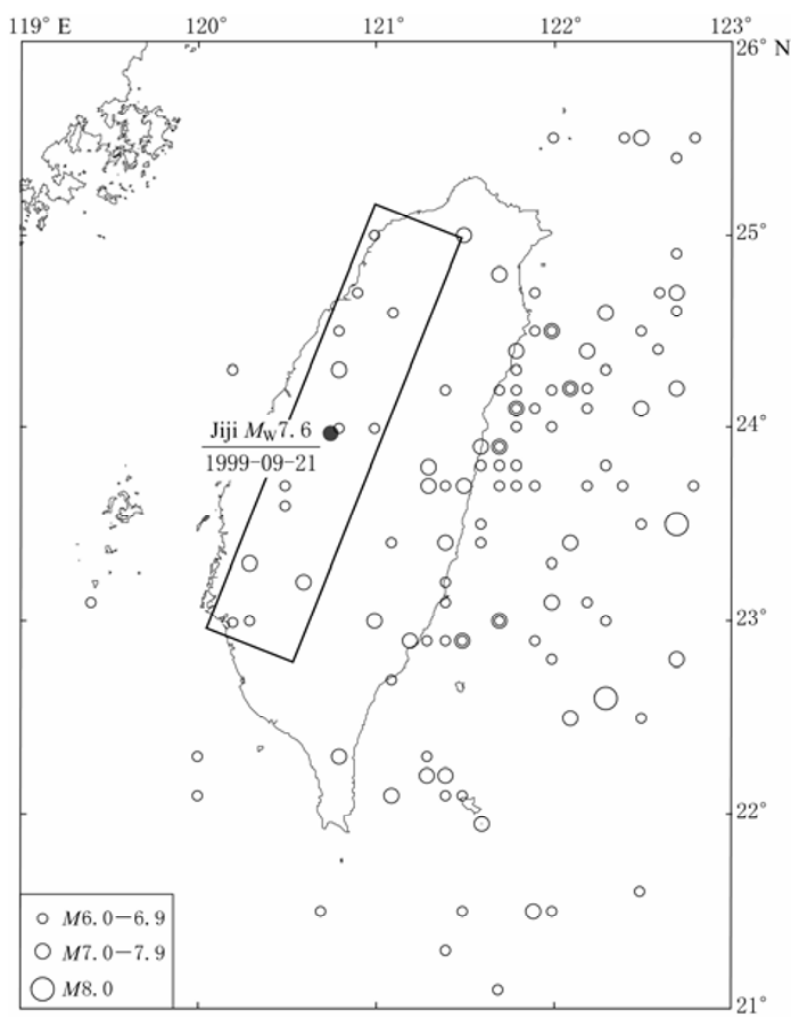

Figure 2 Spatial distribution of $M \geq 6$ earthquakes in Taiwan island from 1900 to 1999 (from China Earthquake Networks). The rectangular denotes the western seismic zone of Taiwan island. 
Table $2 \quad M \geq 7$ earthquakes occurred in Taiwan island

\begin{tabular}{rccccl}
\hline No. & $\begin{array}{c}\text { Date } \\
\text { a-mo-d }\end{array}$ & Lat. ${ }^{\circ} \mathrm{N}$ & Long. ${ }^{\circ} \mathrm{E}$ & $M$ & Location \\
\hline 1 & $1902-11-21$ & 23.0 & 121.0 & 7.2 & NW to Taitung \\
2 & $1909-04-15$ & 25.0 & 121.5 & 7.3 & Near Taipei \\
3 & $1935-04-21$ & 24.3 & 120.8 & 7.1 & Near Taichung \\
4 & $1936-08-22$ & 22.3 & 120.8 & 7.2 & N to Hengchun \\
5 & $1941-12-17$ & 23.3 & 120.3 & 7.0 & Near Tainan \\
6 & $1951-10-22$ & 23.7 & 121.3 & 7.2 & Near Fenglin \\
7 & $1951-10-22$ & 23.8 & 121.3 & 7.1 & Near Fenglin to Tainan \\
8 & $1964-01-18$ & 23.2 & 120.6 & 7.0 & N to Ilan \\
9 & $1994-06-05$ & 24.8 & 121.7 & 7.0 & Near Jiji \\
\hline
\end{tabular}

$40 \mathrm{~km}$ to the $M 7.1$ earthquake in 1935 (Figure 1). In addition, it should be pointed out that the epicenter of the M6.2 earthquake occurred on January 5, 1917 almost coincided with the epicenter location of the $M_{\mathrm{W}} 7.6$ earthquake occurred on September 21, 1999. The time interval between the two earthquakes is 82 years.

\section{$3 M \geq 5$ seismicity gap and $M \geq 4$ seismic quiescence before the Jiji earthquake}

\subsection{Data source}

The earthquake catalogues used in the paper are China Earthquake Catalogue (23 Century BC-1969) (Gu, 1983a), China Earthquake Catalogue (1970-1979) (Gu, 1983b), China Historical Strong Earthquake Catalogue (23 Century BC-1911) (Department of Seismic Hazard Prevention, China Seismological Bureau, 1995), China Current Earthquake Catalogue (1912-1990) (Department of Seismic Hazard Prevention, China Seismological Bureau (1999) and China Earthquake Catalogue Monthly edited by Center for Analysis and Prediction, China Earthquake Administration.

The above-mentioned literatures are the earthquake catalogues widely used in the seismological circle in China at present. The seismic basic parameters of time, location and magnitude of $M \geq 5$ earthquakes are taken from the former four literatures and the basic parameters of $M<5$ earthquakes are drawn from the China Earthquake Catalogue Monthly edited by Center for Analysis and Prediction of China Earthquake Administration. One of the principles for compiling the China Earthquake Catalogue Monthly is that the basic parameters of $M \geq 5$ earthquakes are from the data observed by China Earthquake Networks and those of $M<5$ earthquakes are from the data obtained by the regional earthquake networks.

\subsection{Data analysis and results}

From the analysis of time sequence and spatial pattern of seismic activities occurred in Taiwan before the 1999 Jiji $M_{\mathrm{W}} 7.6$ earthquake, it has been discovered that the seismicity in the central part of Taiwan is characterized by the following obvious anomalies.

In the first 50 years of the 20th century, the $M \geq 6$ seismic activities were quite active along the western seismic zone with an average interval of less than 2 years and the maximum intensity of $M 7.1$. After that, the intensive seismicity turned to be quiescent gradually. In the period from 1965 to 1997 , along the western seismic zone, only one M6 earthquake occurred on March 12, 1991 to the east of Tainan. 14 months before the Jiji $M_{\mathrm{W}} 7.6$ earthquake, a $M 6.3$ earthquake occurred on July 12, 1998 in Chia-i county, which is about $40 \mathrm{~km}$ from the epicenter of Jiji earthquake. In the period of about 100 years, the seismicity in the western seismic zone went through a process of activeness - quietness intensiveness (Figure 3).

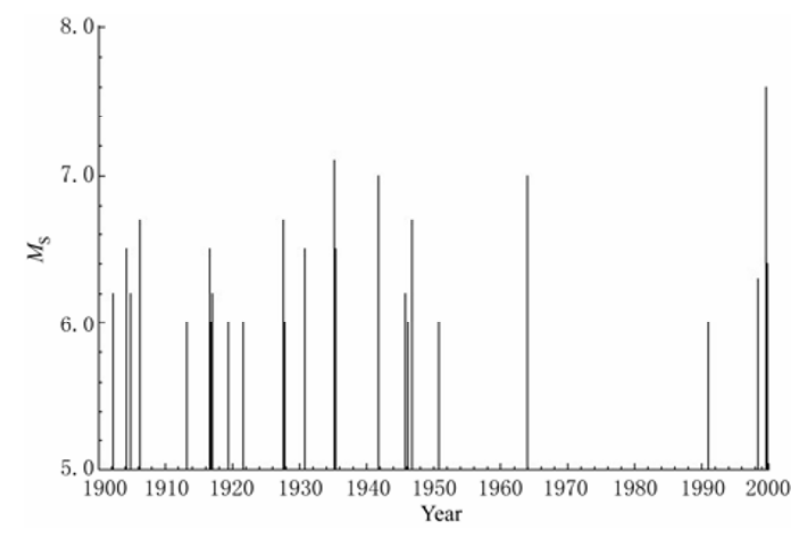

Figure 3 Time sequence of $M \geq 6$ earthquakes occurred since 1900 along the western seismic zone of Taiwan island.

Consistent with the $M \geq 6$ seismic quiescence along the above-mentioned western seismic zone, an elliptic seismicity gap of $M \geq 5$ earthquakes (indicated by circles in Figure 4) had formed gradually in the central part of 
Taiwan in a period as long as 24 years. This seismicity gap remained for eight years till the occurrence of 1999 Jiji $M_{\mathrm{W}} 7.6$ earthquake. With a length of $140 \mathrm{~km}$ for its major axis and a trend of NW, this elliptic seismicity gap obliquely crossed with the western seismic zone.
And it is consistent with the trend of relative movements of the Eurasia plate and the Philippine Sea plate in the southwestern part of Taiwan. After the occurrence of Jiji $M_{\mathrm{W}} 7.6$ earthquake, aftershocks (shown by solid circles in Figure 4) filled the gap.

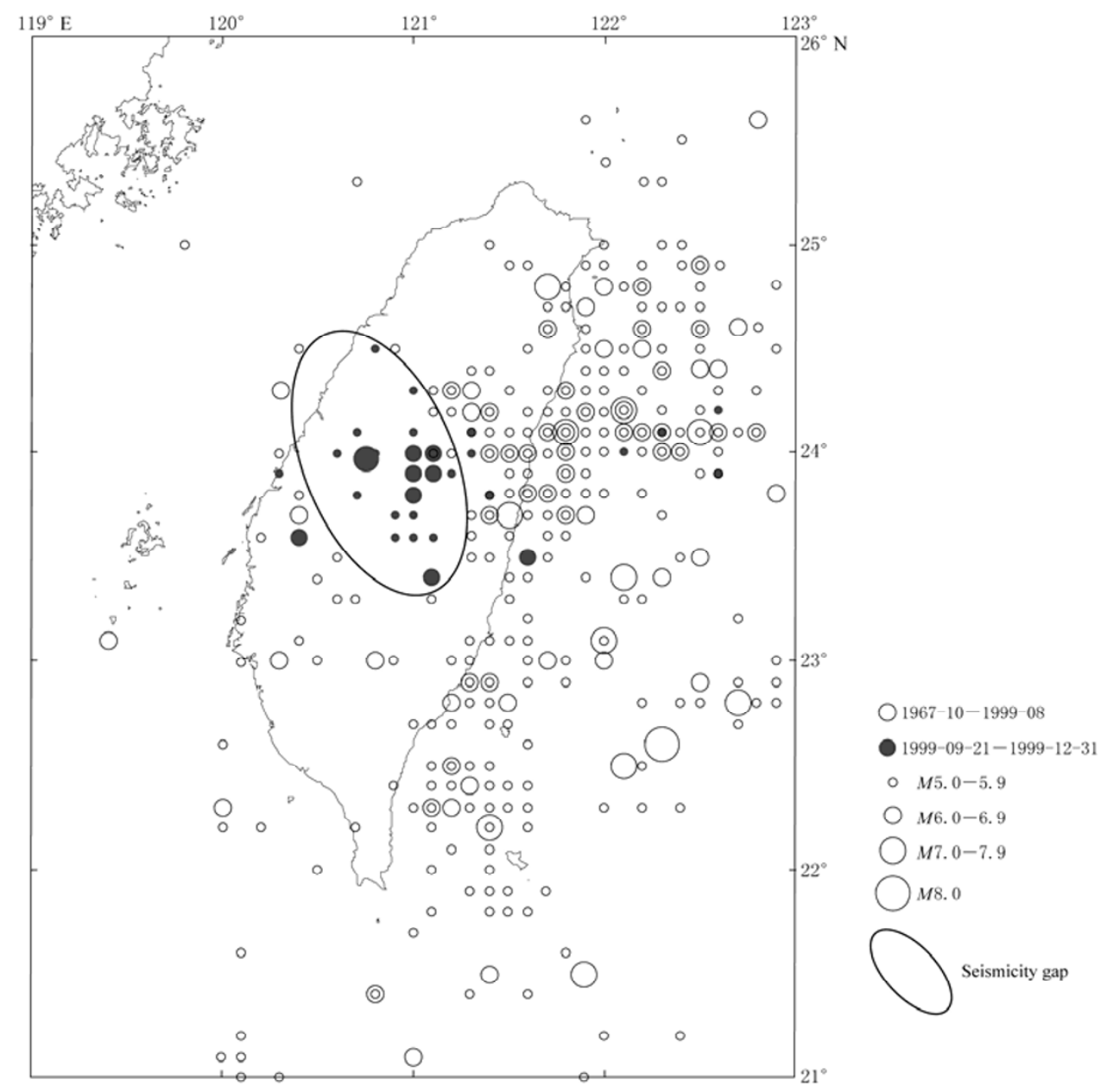

Figure 4 Distribution pattern and seismicity gap of $M \geq 5$ earthquakes occurred in Taiwan island since October of 1967.

Considering from a time scale of several years, the $M \geq 4$ seismicity was relatively quiescent (the solid circles in Figure 5) since the year 1997 in the northwestern part of Taiwan (the rhombic area in Figure 5) till the occurrence of the 1999 Jiji $M_{\mathrm{W}} 7.6$ earthquake. The quiescence was as long as 32 months, while before the year 1997, $M \geq 4$ earthquakes frequently occurred in this area (the circles in Figure 5).

The seismic quiescent area is rather large, but it can be seen clearly from the time sequence of $M \geq 4$ earthquakes shown in Figure 6 that the distribution of earthquakes occurred in the past are basically homogeneous. However, the $M \geq 4$ seismicity suddenly disappeared before the Jiji $M_{\mathrm{W}} 7.6$ earthquake, showing a kind of ten- dency variation of $M \geq 4$ seismicity pattern. Moreover, the $M \geq 4$ seismic quiescence appeared in the period before 1991 shown in Figure 6 might be related to the M6.0 earthquake occurred to the east of Tainan on March 12, 1991.

The Jiji $M_{\mathrm{W}} 7.6$ earthquake occurred in the eastern part of $M \geq 5$ seismicity gap and at the southern end of $M \geq 4$ seismic quiescent area. The seismicity on the south side of the quiescent area is stronger than that on the north side. The M6.3 earthquake occurred on July 17, 1998 in Chia-i county, which is about $40 \mathrm{~km}$ to the south of Jiji $M_{\mathrm{W}} 7.6$ earthquake's epicenter, indicates that the rupture process of regional medium has a trend of extending from the south to the north. It is interesting 


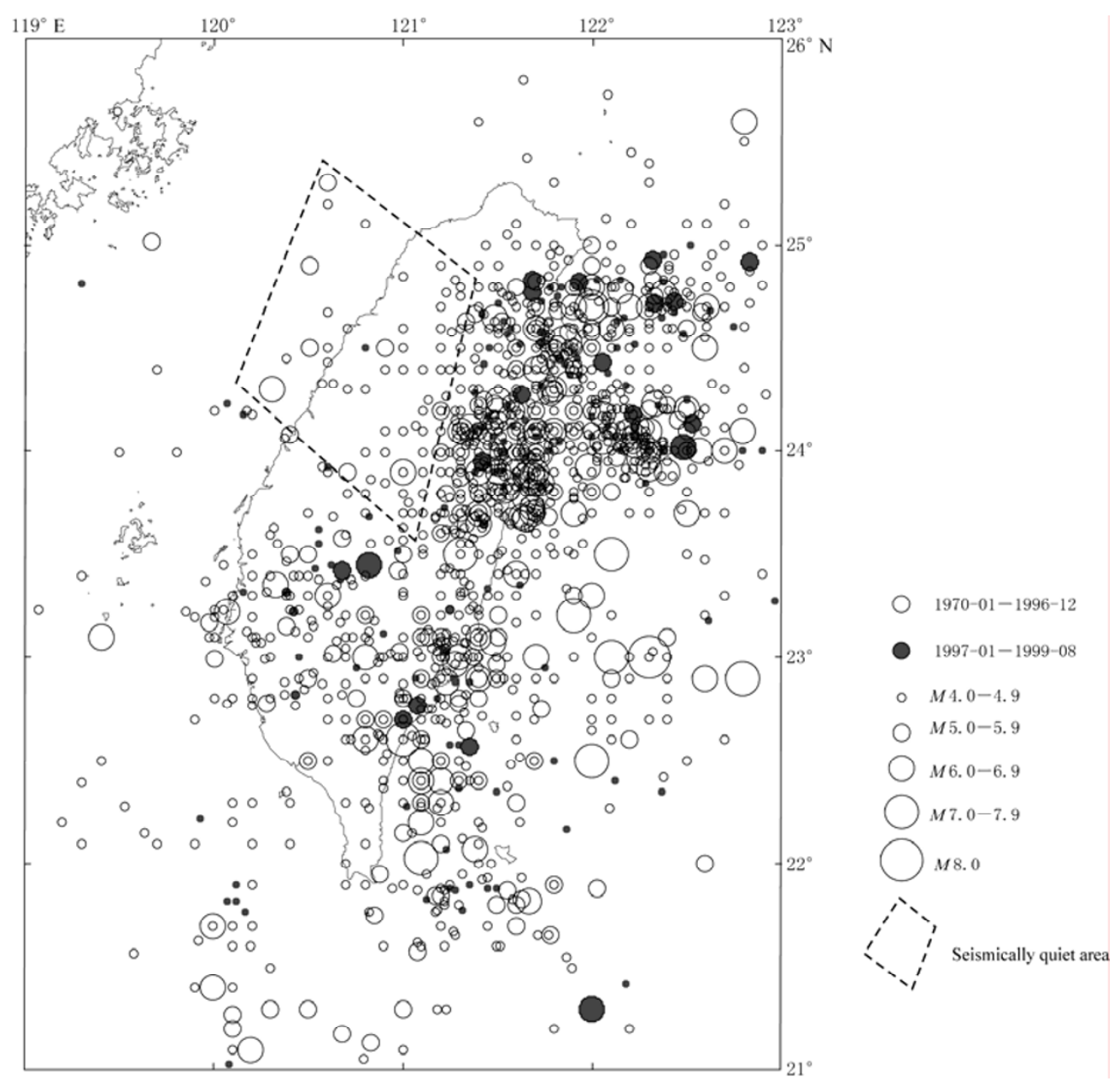

Figure $5 M \geq 4$ seismic quiescent area near the epicenter of $1999 \mathrm{Jiji} M_{\mathrm{W}} 7.6$ earthquake since 1997.

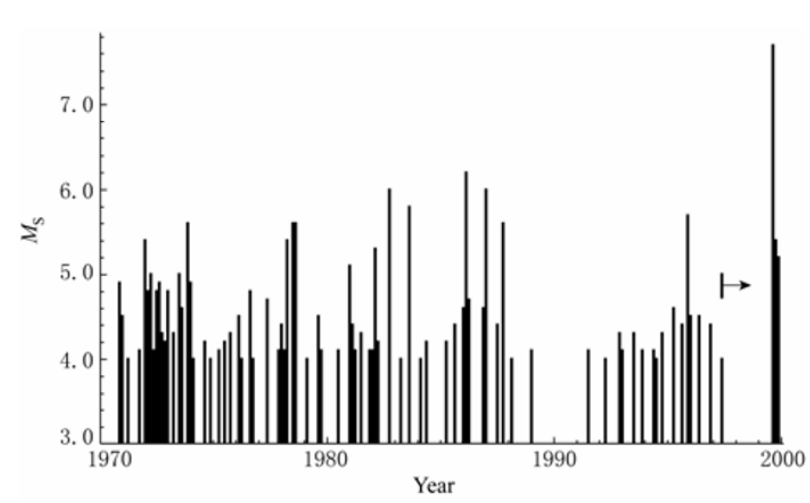

Figure 6 Time sequence of $M \geq 4$ earthquakes occurred in the seismic quiescent area since 1970 .

to note that, in the results obtained from the study on the Jiji earthquake sequence and the focal rupture process reported by $\mathrm{Xu}$ et al (1999), the $M \geq 4.5$ aftershocks of Jiji $M_{\mathrm{W}} 7.6$ earthquake are generally distributed along the zone with a length of $100 \mathrm{~km}$ to the north of the mainshock. The rupture extends basically from the south to the north along one side. Huang (2000) reconstructed a 2-D spatial seismic wavefield with the data of strong ground motion. The result indicates that after the initial rupture of Jiji earthquake, the focal rupture spreads towards the north end of the fault, resulting in the asymmetric propagation of wavefront from the fault plane to the northwest direction.

Qualitative analysis considered that the $M \geq 5$ seismicity gap and the $M \geq 4$ seismic quiescence appeared before the Jiji $M_{\mathrm{W}} 7.6$ earthquake might be related to the seismogenic mechanical condition of a great earthquake, and its spatial range is related to the seismogenic body to a certain extent. The anomalous variation in the spatial pattern of regional seismicity before an earthquake is well consistent with the coseismic focal rupture process in a certain sense. 


\section{Discussion and conclusions}

It is well known that the seismicity gap hypothesis was proposed respectively by Fedotov (1965) and Allen et al (1965) based on the study of space-time pattern of earthquakes occurred along the marginal seismic zones of the Pacific plate. From then on, many seismologists have made extensive studies on seismicity gap and proposed different viewpoints (e.g., Sykes, 1971; Kelleher et al, 1973; Kagan and Jackson, 1991; Nishenko and Sykes, 1993). The pattern of regional seismicity gap appearing before a great earthquake is a kind of manifestation of stress concentration in the seismogenic process, reflecting the secular development and variation of stress and strain in the seismogenic zone. And the seismic quiescence before great earthquakes is listed as one of the five basic precursors by IASPEI. This kind of phenomenon can be found before many great earthquakes. For example, Wang et al (1998), Wang and Zhao (1998) proposed that before the Zhangbei M6.2 earthquake occurred on January 10, 1998 in China, there was a $M \geq 4$ seismic quiescence lasting as long as eight years near the epicenter. However, there are also negative examples. A number of moderately strong earthquakes did not occur in the seismicity gap. Some of them occurred in the location with continuously strengthening seismic activities and some of them occurred in the location without corresponding pre-earthquake precursory seismicity in the vicinity of epicenter. The possible reasons are two: the first is that the earthquake is not an independent event but the precursor activity before a great earthquake; the second is the earthquake is an independent event, but the medium in the region might be broken (with higher inhomogeneity). In this circumstance, earthquake might occur while the strain has not accumulated to a high extent. So, stronger earthquakes might not occur in such an area.

Generally speaking, the plate-margin seismicity gap and the intraplate seismicity gap are different in the spatial pattern. The former is characterized by periodic gap between great earthquakes (I-type gap), while the latter is predominated by circularly confined gap of low intensity under a certain space-time conditions (II-type gap). Considering from the regularity of seismic activity in the western part of Taiwan, the seismicity gap appeared before the $1999 \mathrm{Jiji} M_{\mathrm{W}} 7.6$ earthquake belongs to the second type. The major-axis direction of the seismicity gap before the Jiji $M_{\mathrm{W}} 7.6$ earthquake was consistent with the trend of the western seismic zone and its origin is closely related to the surrounding tectonic conditions. It means that the stress field of the focal region was stable, or it was in the quasi-static stage in the developing process of a great earthquake. The $M \geq 4$ seismic quiescence appeared near the epicenter of Jiji $M_{\mathrm{W}} 7.6$ earthquake since 1997 indicates that the stress and strain of seismogenic medium is in a critical locked state in the late seismogenic period. The evolution processes of $M \geq 5$ seismicity gap and the $M \geq 4$ seismic quiescence have shown a better consistence with the rupture process of Jiji $M_{\mathrm{W}} 7.6$ earthquake, which indicates that an inevitable internal relationship must exist between the regional seismicity and the development of Jiji $M_{\mathrm{W}} 7.6$ earthquake.

The relationship between the $M 6.2$ earthquake occurred on January 5, 1917 and the $M_{\mathrm{W}} 7.6$ earthquake occurred on September 21, 1999 will not be discussed here. However, this is a phenomenon occurred quite often in Chinese mainland. The authors have made a preliminary investigation that among the $19 M \geq 7$ earthquakes taken place in North China since the year 1000, M5 or M6 earthquakes occurred before 18 of them near the epicenter with a time interval of several years to tens years.

The authors therefore conclude from the seismogenic process of the $1999 \mathrm{Jiji} M_{\mathrm{W}} 7.6$ earthquake that its seismogenic mechanism has the characteristics of intraplate earthquake, and its variation of regional seismicity occurred before the earthquake is similar to those of the earthquakes occurred in Chinese mainland.

\section{References}

Allen C R, Saint-Amand P, Richter C F and Nordquist J M (1965). Relationship between seismicity on geologic structure in Southern California region. Bull Seism Soc Amer 55: 753-797.

Angelier J (1986). Preface. Geodynamics of the Eurasia-Philippine Sea plate boundary. Tectonophysics 125: IX-X.

Department of Seismic Hazard Prevention, China Seismological Bureau (1995). China Historical Strong Earthquake Catalogue (23 Century BC-1911). Seismological Press, Beijing, 514pp (in Chinese).

Department of Seismic Hazard Prevention, China Seismological Bureau (1999). China Current Earthquake Catalogue (1912-1990). China Scientific and Technological Press, Beijing, 673pp (in Chinese).

Fedotov S A (1965). Regularities of distribution of strong earthquake in Kamchatka, the Kuril Island and northeast Japan. Tr Inst Fiz ZeMi Acad Nauk SSSR 36: 66-93.

Gu G X (1983a). China Earthquake Catalogue (23 Century BC-1969). Science Press, Beijing, 890pp (in Chinese).

Gu G X (1983b). China Earthquake Catalogue (1970-1979). Seismological Press, Beijing, 334pp (in Chinese).

Huang Bor-Shouh (2000). Two-dimensional reconstruction of the surface ground motions of an earthquake: the September 21, 1999, Chi-Chi, Taiwan earthquake. Geophys Res Lett 27(18): 3 025-3 028.

Kagan Y Y and Jackson D D (1991). Seismic gap hypothesis: Ten years after. J Geophys Res 96: 21 419-21 431. 
Kelleher J, Sykes L R and Oliver J (1973). Possible criteria for predicting earthquake locations and their application to major plate boundaries of the Pacific and the Caribbean. J Geophys Res 78: 2 547-2 585.

Nishenko S P and Sykes L R (1993). Comment on "Seismic gap hypothesis: Ten years after" by Y. Y. Kagan and D. D. Jackson. J Geophys Res 98: 9 099-9 916.

Seno T (1977). The instantaneous rotation vector of the Philippine Sea plate relative to the Eurasian plate. Tectonophysics 42: 209-226.

Sykes L R (1971). Aftershock zones of great earthquakes, seismicity gaps, and earthquake prediction for Alaska and the Aleutians. $J$ Geophys Res 76: $8021-8041$.

Wang J G, Wu X Z and Diao G L (1998). Regional seismicity anomaly before M6.2 Zhangbei-Shangyi earthquake of Jan. 10, 1998 and its prediction. Earthquake 18(4): 383-390 (in Chinese with English abstract).
Wang J G and Zhao G M (1987). Seismic activity gap before strong earthquakes. North China Earthquake Sciences 5(Suppl.): 86-94 (in Chinese).

Xu L S, Yang Z X and Chen Y T (1999). Chi-Chi earthquake sequence and preliminary analysis of its focal fracture process. In: Collected Papers of 20th Anniversary of State Seismological Society. Seismological Press, Beijing, 97-110 (in Chinese).

Ye Y T and Huang W J (1992). Study on seismic hazard prevention in Taiwan. In: Proceedings of First Across-the-Straits Conference on Earthquake (1st ASCOE). Seismological Press, Beijing, 135-162 (in Chinese). 